\title{
Influencia de la obligación legal de indemnizar al cónyuge perjudicado en la duración y tramitación del proceso de divorcio por «causal de separación de hecho», provincia de La Convención, Cusco 2009-2012
}

Liliana Coronado Gamarra

Magíster en Derecho Civil y Procesal Civil, por la Universidad Nacional San Antonio Abad del Cusco Docente Contratada a tiempo completo por la Universidad Andina del Cusco Filial Quillabamba, La Convención-Cusco

Escuela Profesional de Derecho

\section{RESUMEN}

\section{Objetivo general}

Determinar si la obligación legal de indemnizar al cónyuge perjudicado, influye en la duración y tramitación del proceso de divorcio por la causal de 'separación de hecho', en la Provincia de La Convención, Cusco, años 2009-2012.

\section{Tipo de estudio, técnicas y métodos de investigación}

Se realizó un estudio cualitativo-documental, se aplicaron técnicas de análisis bibliográfico y análisis documental de expedientes judiciales, se empleó el método funcional del derecho.

\section{Resultados}

La obligación legal de indemnizar al cónyuge perjudicado influye en la duración y tramitación del proceso de divorcio por la causal de separación de hecho, extendiéndolo y tornándolo complejo, en La Convención, Cusco, 2009 - 2012.

\section{Conclusiones}

El proceso de divorcio por separación de hecho — perteneciente al sistema de 'divorcio remedio'-, al poseer como acumulación legal obligatoria la indemnización en caso de perjuicio, en la práctica judicial pierde su tendencia y se asemeja a un proceso de divorcio por causal, perteneciente al sistema de 'divorcio sanción', por la duración y grado de beligerancia. La recomendación fundamental está referida a la tramitación de los procesos de divorcio por separación de hecho en una vía procedimental más corta y a la promoción de la pretensión autónoma de indemnización al cónyuge perjudicado, en un proceso independiente mediante una reforma legislativa.

Palabras clave: separación de hecho, divorcio remedio, indemnización a cónyuge perjudicado. 


\section{ABSTRACT}

General objective

To determine if the legal obligation to indemnify the injured spouse influences the duration and processing of the divorce process for the cause of 'de facto separation', in the province of La Convención, Cusco, 2009-2012.

Type of study, techniques and research methods

A qualitative-documental, correlational and explanatory study was carried out. In addition, techniques of bibliographic analysis and documentary analysis of court records were applied, using the functional method of law.

Results

The legal obligation to indemnify the injured spouse influences the duration and processing of the divorce process by reason of de facto separation, extending it and making it complex in La Convención, Cusco, 2009-2012.

Conclusions

The process of divorce by de facto separation - pertaining to the system of 'divorce remedy'to possess as legal compulsory accumulation the indemnification in case of prejudice, in judicial practice loses its tendency and resembles a process of divorce by causal, Belonging to the system of 'divorce sanction', for the duration and degree of belligerence. The fundamental recommendation concerns the processing of divorce proceedings by de facto separation, on a shorter procedural route and the promotion of the autonomous claim of compensation to the injured spouse, in an independent process through a legislative reform. Key words: De facto separation, remedy divorce, compensation to injured spouse.

\section{INTRODUCCIÓN}

El divorcio no es un mal en sí, sino una forma legal de remediar un matrimonio que no cumple con sus fines y por ende, genera una crisis familiar afectando a la sociedad. Es por ello que su tratamiento en las legislaciones no debe ser de sesgo inculpatorio estableciendo culpables o inocentes, sino por el contrario, se debe tender a solucionar el conflicto de la manera 
"menos conflictiva" que se pueda. Esa sería la esencia del 'divorcio remedio', que fue acogida en nuestro país en el año 2001, con la incorporación de 'la separación de hecho como causal de divorcio', que tuvo como fundamento la existencia de casi un millón de personas en condición de separados que requerían regularizar su situación teniendo en cuenta, que la indefinición de su estado civil generaba consecuencias graves en las nuevas familias que se formaban, especialmente en los hijos y, también, sobre sus bienes. Dicha causal —que pertenece a la tendencia del divorcio remedio-, estuvo destinada a dar solución jurídica a esos casos. Sin embargo, en el Congreso de la República las comisiones de Reforma de Códigos y de la Mujer, producto del debate realizado introdujeron modificaciones al texto sustitutorio elaborado por la Comisión de Justicia, de los proyectos de ley tendientes a la incorporación de la separación de hecho como causal de divorcio agregando, entre otros aspectos, una "cláusula de dureza", como lo mencionó la doctora Lourdes Flores Nano, integrante de la Comisión de la Mujer, referida al contenido del artículo 345 A del Código Civil, que no ha sido muy comprendido por nuestros operadores del derecho.

Por lo que, casi a diez años de la dación de la ley, se llevó a cabo el Tercer Pleno Casatorio en lo Civil, en el que se precisó la naturaleza jurídica de la indemnización al cónyuge perjudicado, como:

[...] la de una obligación legal, cuya finalidad es corregir un evidente desequilibrio económico e indemnizar el daño a la persona, resultante de la separación de hecho o del divorcio en sí, su fundamento no es la responsabilidad civil contractual o extracontractual sino la equidad y la solidaridad familiar. (p. 210).

Así como, la posibilidad de su incorporación, de parte o de oficio, en los procesos de divorcio por separación de hecho. (Sentencia dictada en el Tercer Pleno Casatorio Civil realizado por las Salas Civiles, Permanente y Transitoria de la Corte Suprema de Justicia de la República del Perú, 2010).

En la práctica, consideramos que todavía no se ha dado una solución completa al tema del divorcio en el Perú, pues no hemos acogido el sistema de divorcio remedio en toda su magnitud y, por ello, a una causal de divorcio que, supuestamente, corresponde a dicha tendencia, la tenemos rodeada de aspectos relacionados con la predisposición del divorcio 
sanción; así lamentablemente, es entendido en el plano fáctico, aunque algunos doctrinarios sostengan lo contrario.

Nuestra posición se basa en el ejercicio del derecho de familia y se remonta todavía a los primeros años después de la promulgación de la ley $n^{\circ}$ 27495, al asumir patrocinios judiciales en procesos de divorcio por separación de hecho, en los cuales al incorporarse la pretensión de indemnización surgieron las interrogantes: ¿cuál de los dos cónyuges es el perjudicado? ¿Cuál será el monto de su indemnización? ¿Cómo se probará el perjuicio y en base a qué criterios el juzgador establecerá un monto de dinero o la adjudicación de bienes? Ello porque, a pesar de que en la mayoría de los casos los cónyuges se encontraban de acuerdo con el divorcio, el conflicto se presentaba en la pretensión acumulada. El tiempo transcurrió y las interrogantes que surgieron en nosotros $-\mathrm{y}$ seguramente en algunos otros operadores del derecho- fueron, de alguna manera, resueltas con el pleno casatorio; sin embargo, nos suscribimos a la posición de Luis Genaro Alfaro Valverde, pues consideramos que todavía la regulación normativa de la indemnización en la separación de hecho adolece de imprecisiones y omisiones, tanto de orden sustantivo como procesal, lo que puede traducirse en un falso concepto de esta, entendiéndola más que como un mecanismo destinado a evitar inequidades patrimoniales manifiestas entre cónyuges, como una sanción aplicada sin límite temporal y asociada a la culpabilidad de uno de ellos; de tal manera, pensamos como el autor en mención, que aún queda una larga tarea doctrinal y jurisprudencial por hacer, para afinar coherentemente el instituto de la indemnización al cónyuge perjudicado en el divorcio por separación de hecho. (Alfaro Valverde, 2011, p.142)

Actualmente, está determinado que la pretensión de divorcio por la causal de separación de hecho debe transitar por el denominado 'proceso de conocimiento' que, como se sabe, es el proceso de cognición plena, caracterizado por tener un diseño de audiencias desarrolladas en plazos amplios, porque a través de él se debaten, por lo general, pretensiones sumamente complejas o de gran estimación patrimonial que ameritan un debate amplio entre las posiciones de las partes, para procurar al órgano jurisdiccional un grado de certeza tal que le permita declarar o constituir derechos. 
El divorcio por la causal de separación de hecho, se basa en una causa no culposa, sustentada en la inexistencia de uno de los elementos constitutivos primarios del matrimonio: la vida en común. Esta causal es objetiva al demostrarse un hecho real y directo, la falta de convivencia en un plazo determinado e ininterrumpido se presenta como una fórmula necesaria para incorporar la teoría del divorcio-remedio por la propia realidad social, familiar, económica y política que hoy vive nuestro país. Esta causal pertenece al sistema objetivo no inculpatorio del divorcio remedio, busca resolver un problema social claramente identificado: el mantener formalmente, una relación conyugal inexistente real, fundada en falsas verdades.

El presente trabajo de investigación trata, precisamente, sobre la influencia de la obligación legal de indemnizar al cónyuge perjudicado en la duración y tramitación del proceso de divorcio por la causal de separación de hecho, en la provincia de La Convención, Cusco durante los años 2009 a 2012, y de cómo es que esta acumulación afecta a un tipo de proceso de divorcio que, perteneciendo a la tendencia del divorcio remedio, se desnaturaliza en su esencia y se convierte en un proceso de divorcio con matices de divorcio sanción, extendiéndolo en su plazo y tornándolo complejo, situaciones que consideramos, deterioran más aún las relaciones familiares ya resquebrajadas; por lo que, detectado este problema, proponemos una modificatoria a la norma en cuestión.

\section{MATERIALES Y MÉTODOS}

El presente artículo deriva de una tesis para optar al grado académico de Magíster en Derecho Civil y Procesal Civil, en la Escuela de Posgrado de la Universidad Nacional de San Antonio Abad del Cusco.

La población y muestra de la presente investigación son los 27 expedientes de divorcio por separación de hecho tramitados en el Juzgado de Familia de La Convención durante los años 2009 a 2012. En setiembre del año 2013 recurrimos a la juez decana de la sede de la Corte Superior de Justicia del Cusco, en la ciudad de Quillabamba, doctora Mariliana Cornejo Sánchez, Juez Titular del Juzgado de Familia, la que nos autorizó el acceso al Archivo Modular y Archivo Central y dispuso que personal del juzgado a su cargo y del Archivo 
Modular y Central, nos brindaran las facilidades para acceder a los expedientes, iniciando así nuestro trabajo de recolección de datos en fichas o guías preelaboradas.

Para lograr obtener los datos de los expedientes judiciales de divorcio por separación de hecho tramitados en el Juzgado de Familia de La Convención durante los años 2009 al 2012, previamente obtuvimos la relación de todos los procesos ingresados en dicho periodo al juzgado mencionado de los cuales, a su vez, obtuvimos el número de procesos de divorcio en general y de separación convencional y divorcio ulterior, a partir de ellos en el sistema computarizado de la sede de corte, revisamos cada proceso de divorcio por causal para obtener los números y ubicación de los expedientes de divorcio por causal de separación de hecho, posteriormente, acudimos al Archivo Modular y Central para obtener los datos de cada expediente de divorcio por separación de hecho.

Los instrumentos de recolección de datos que constituyen las fichas o guías de análisis documental para recabar los datos de los expedientes judiciales fueron elaborados para medir las variables contenidas en las hipótesis, sobre la base en los indicadores de las mismas y nos permitieron recoger datos e información necesaria para resolver los problemas planteados y verificar las hipótesis.

Al analizar cada expediente de divorcio por separación de hecho, hemos observado las normas objeto de estudio vivas o en acción o dicho en otras palabras cómo han sido aplicadas e interpretadas o realizadas. En efecto, en el presente trabajo de investigación hemos conocido la realidad a través de manifestaciones vivas del derecho: Los expedientes judiciales y no solo a través de la ley.

Todo lo manifestado guarda relación con las características del método funcional de la investigación jurídica desarrolladas por Ramos Núñez (2014) en su obra «Cómo hacer una Tesis en Derecho».

Una vez recolectada la información tanto teórica como fáctica, se procedió a su análisis e interpretación, se escogió la información que se consideró de mayor importancia para la investigación seleccionando la más actualizada y relevante. Este procedimiento se realizó, 
principalmente, en la elaboración del marco teórico, asimismo los datos obtenidos de los expedientes judiciales fueron analizados e interpretados en base a su tabulación, utilizando tablas simples o lineales y gráficos estadísticos en barra y circulares. A través de estos procedimientos se comprobaron las hipótesis, se cumplieron los objetivos y se arribaron a las conclusiones.

\section{RESULTADOS}

\section{Primera hipótesis específica}

Sobre la primera hipótesis específica: «La acumulación de la pretensión de indemnización al cónyuge perjudicado, influye en la duración y tramitación del proceso de divorcio por la causal de separación de hecho, extendiéndolo y tornándolo complejo», tenemos lo siguiente:

La mayor cantidad de los procesos de divorcio por separación de hecho, que presentan acumulación de pretensión de indemnización al cónyuge perjudicado, se encuentran en etapa probatoria (5) que equivalen al 38,46\%, y se encuentran en tramitación 8 (etapas postulatoria, probatoria y decisoria) que equivalen al 61,54\% (sumatoria de los porcentajes de expedientes ubicados en cada etapa) y solo un $38,46 \%$, han sido sentenciados. El $100 \%$ han superado el año de duración.

Sobre el tiempo de duración de los procesos de divorcio por separación de hecho con acumulación de indemnización al cónyuge perjudicado, tenemos que, el 61,54 \% de dichos procesos (8), han sobrepasado los dos años; y el $100 \%$ de los procesos han sobrepasado el año.

Un proceso de divorcio por separación de hecho de tendencia divorcio-remedio en el que se deba analizar si se produjo el cese de la convivencia por el tiempo exigido por ley o no, no debería sobrepasar el año de duración, en el caso de la presente investigación tenemos que todos los procesos que constituyeron la población de la investigación han superado ese plazo. Estos procesos poseen la acumulación de la pretensión indemnizatoria. 
En los procesos de divorcio por separación de hecho, en los que se acumula la pretensión de indemnización al cónyuge perjudicado, la parte contraria tiene como posición la de negar el otorgamiento de la indemnización en un alto porcentaje de 92,31\%.

Sobre el objeto de controversia, tenemos que en el 92,31\% de procesos, el objeto de la controversia no es la procedencia del divorcio, sino la determinación del cónyuge perjudicado y el monto que le correspondería por indemnización.

De todo lo mencionado, tenemos que en este tipo de procesos de divorcio en los que se presenta acumulación de la pretensión de indemnización al cónyuge perjudicado, poseen un trámite más extendido y complejo que los procesos en los que no se presenta esta acumulación

Estos resultados se encuentran relacionados con la presencia de posiciones antagonistas - 0 de resistencia de las partes-, así como con la presencia de mayor actividad probatoria referida, precisamente, a la pretensión acumulada. Tal situación le otorga un matiz de divorcio-sanción al divorcio por separación de hecho, que desnaturaliza la esencia de divorcio-remedio de la causal.

Con respecto a los procesos que no presentan acumulación de pretensión de indemnización al cónyuge perjudicado, la gran mayoría de estos se encuentran resueltos $(83,33 \%)$.

El $75 \%$ de los procesos en los que no se acumula la pretensión de indemnización al cónyuge perjudicado, no supera el año de tramitación, tal característica es la esperada en la tramitación de un proceso de divorcio de tendencia remedio.

El objeto de la controversia - en los procesos en los que no se acumula la pretensión de indemnización al cónyuge perjudicado - en su gran mayoría no se presenta, es decir, un $75 \%$, y solo en el $25 \%$ es objeto de controversia. La procedencia del divorcio, derivado del hecho de que en el proceso judicial se ventila solo la naturaleza del divorcio por separación de hecho (elementos material u objetivo, psicológico y temporal), y no una pretensión que — tal y como está regulada en nuestro sistema - genera ineficiencia por ocasionar posiciones más opuestas en el proceso. 
La interposición de impugnaciones en los procesos en los cuales no se acumula la pretensión de indemnización al cónyuge perjudicado es mínima (16,67 \%), de la cual concluimos que, los procesos de divorcio por separación de hecho en los que no se presenta acumulación de la pretensión de indemnización al cónyuge perjudicado, poseen una tramitación menos extendida y compleja que los procesos en los cuales se presenta esta acumulación.

En consecuencia, podemos afirmar que la obligación legal de indemnizar al cónyuge perjudicado en la Provincia de La Convención, Región Cusco, de 2009 a 2012, influye en la duración y tramitación de los procesos de divorcio por separación de hecho, extendiendo sus plazos y tornando más compleja su tramitación por incrementar su situación discrepante.

Como hemos venido sosteniendo durante el presente trabajo de investigación, el proceso de divorcio por separación de hecho con la acumulación de la pretensión indemnizatoria, en la práctica se asemeja a un proceso de divorcio-sanción, pues los cónyuges — en la mayoría de los casos - se atribuyen conductas culposas llegando a afectar sus derechos a la intimidad personal y familiar, con el único fin de ser considerados "cónyuge perjudicado" y tener el derecho a la indemnización. Al respecto, Calisaya Márquez (2013) sostiene: « [...] en los casos de divorcio-sanción, pero también en el divorcio por separación de hecho, las demandas y contestaciones se ven forzadas a ingresar a los secretos más sórdidos de la intimidad familiar.» (Pp.385-386).

\section{Segunda hipótesis específica}

Sobre la segunda hipótesis específica: «La negación de indemnizar influye en la duración y tramitación del proceso de divorcio por la causal de separación de hecho, extendiéndolo y tornándolo complejo», tenemos lo siguiente:

Los procesos de divorcio por separación de hecho en los que se presenta negación de indemnizar constituyen el 92,31 \% del total de procesos con acumulación de pretensión de indemnización, en consecuencia, los procesos de divorcio por separación de hecho en los que se presenta acumulación de la pretensión de indemnización al cónyuge perjudicado y, además, negación de indemnizar, tienen una duración extendida y un trámite complejo. 
Este proceso, que debería ser menos controversial que los procesos de divorcio por causal, perteneciente a la tendencia divorcio-sanción, no lo es debido a la acumulación de la obligación indemnizatoria. Ello obedecería a una distorsión en la aplicación de la pretensión acumulada referida a su utilización como una suerte de venganza o revancha entre los cónyuges y, en algunos casos, como una sanción por parte de los juzgadores. Sobre este aspecto, Borda (2015) sostiene lo siguiente:

La compensación económica, dará lugar a terribles juicios para obtener el mayor resarcimiento por la ruptura conyugal (...). El divorcio va a originar múltiples conflictos por cuestiones económicas, dado que se va a reclamar (...) una suma de dinero por compensación económica que no es ni más ni menos que una indemnización. (p. 90).

\section{Hipótesis general}

Sobre la hipótesis general: «La obligación legal de indemnizar al cónyuge perjudicado, influye en la duración y tramitación del proceso de divorcio por la causal de separación de hecho», tenemos que al haberse validado las dos hipótesis específicas y, por tanto, cumplido con los dos objetivos específicos, podemos afirmar que se ha dado cumplimiento al objetivo principal: «Determinar si la obligación legal de indemnizar al cónyuge perjudicado influye en la duración y tramitación del proceso de divorcio por la causal de separación de hecho en la Provincia de La Convención, Región Cusco, 2009-2012», pues ha quedado demostrado, que la obligación legal de indemnizar al cónyuge perjudicado sí tiene influencia en la duración y tramitación del proceso de divorcio por la causal de separación de hecho. De esta manera, también se valida la hipótesis general: «La obligación legal de indemnizar al cónyuge perjudicado, influye en la duración y tramitación del proceso de divorcio por la causal de separación de hecho», y por lo tanto, se ha resuelto el problema general: « ¿La obligación legal de indemnizar al cónyuge perjudicado influye en la duración y tramitación del proceso de divorcio por la causal de separación de hecho en la Provincia de La Convención, Región Cusco, 2009-2012?». 
PROCESOS EN LOS QUE SE PRESENTA ACUMULACIÓN DE PRETENSIÓN DE INDEMNIZACIÓN AL CÓNYUGE PERJUDICADO

TABLA N. ${ }^{\circ} 1$ Tiempo de duración de procesos en meses:

CATEGORÍAS FRECUENCIA PORCENTAJE

1.-01-03 meses $0 \quad 0 \%$

2.-04-06 meses $0 \quad 0 \%$

3.-07-09 meses $0 \quad 0 \%$

4.-10-12 meses $\quad 0 \quad 0 \%$

5.-13-15 meses $2 \quad 15,38 \%$

6.-16-18 meses $2 \quad 15,38 \%$

7.-19-21 meses $1 \quad 7,70 \%$

8.-22-24 meses $0 \quad 0 \%$

9.-25-36 meses $5 \quad 38,46 \%$

10.-36... meses $3 \quad 23,08 \%$

$\begin{array}{lll}\text { TOTAL } & 13 & 100 \%\end{array}$

GRÁFICO N. ${ }^{\circ} 1$

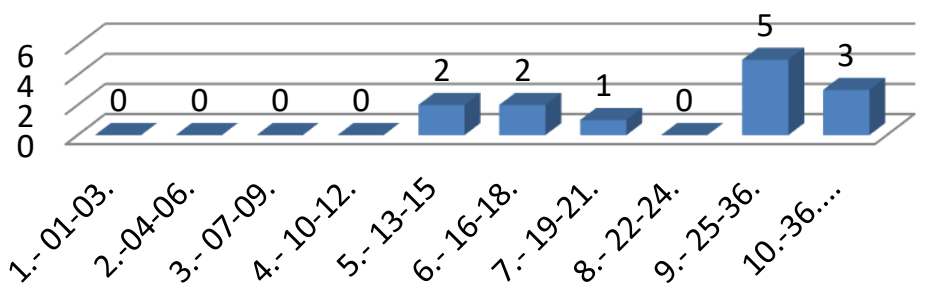

Fuente: Elaboración propia 
TABLA N. ${ }^{\circ} 2$ Sobre el objeto de la controversia

CATEGORÍA

1.-PROCEDENCIA DEL DIVORCIO

2.-DETERMINACIÓN

DEL

CÓNYUGE 12

PERJUDICADO Y MONTO DE INDEMNIZACIÓN

TOTAL
FRECUENCIA PORCENTAJE

1

$7,69 \%$

$92,31 \%$

13

GRÁFICO N. ${ }^{\circ} 2$



Fuente: Elaboración propia

PROCESOS EN LOS QUE NO SE PRESENTA ACUMULACIÓN DE PRETENSIÓN DE INDEMNIZACIÓN AL CÓNYUGE PERJUDICADO

TABLA N. ${ }^{\circ} 3$ Tiempo de duración de procesos en meses:

CATEGORÍAS FRECUENCIA PORCENTAJE

1.-01-03 meses $0 \quad 0 \%$

2.-04-06 meses $0 \quad 0 \%$

3.-07-09 meses $9 \quad 75 \%$

4.-10-12 meses $2 \quad 16,66 \%$

5.-13-15 meses $1 \quad 8,33 \%$

6.-16-18 meses $0 \quad 0 \%$

7.-19-21meses $0 \quad 0 \%$ 


$\begin{array}{lll}\text { 8.-22-24 meses } & 0 & 0 \% \\ 9 .-25-36 \text { meses } & 0 & 0 \% \\ 10 .-36 \ldots \text { meses } & 0 & 0 \% \\ \text { TOTAL } & 12 & 100 \%\end{array}$

\section{GRÁFICO N. ${ }^{\circ} 3$}

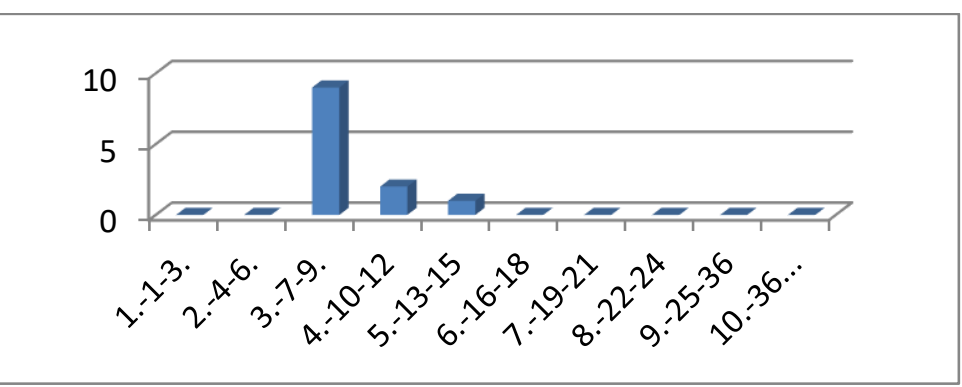

Fuente: Elaboración propia

TABLA N $^{\circ} 4$ Sobre el objeto de la controversia

CATEGORÍA FRECUENCIA PORCENTAJE

1.- PROC. DEL DIV. $3 \quad 25 \%$

2.- NINGUNA $9975 \%$

$\begin{array}{lll}\text { TOTAL } & 12 & 100 \%\end{array}$

GRÁFICO N. ${ }^{\circ} 4$

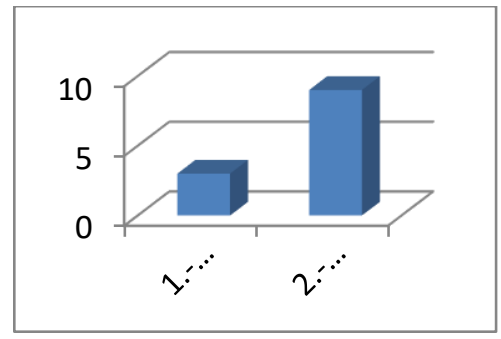

Fuente: Elaboración propia 
Cabello Matamala (2001, p.413), sostiene que existe un tratamiento inculpatorio de la regulación de los efectos del divorcio por separación de hecho en nuestro país. Consideramos que se refiere, en parte, a las consecuencias de la acumulación de la pretensión indemnizatoria al proceso de divorcio por separación de hecho, pues esta genera «debate probatorio destinado a la determinación del cónyuge perjudicado». Es precisamente esta circunstancia la que ejerce influencia procesal en la tramitación del proceso de divorcio por separación de hecho, lo cual se encuentra corroborado en el presente trabajo de investigación.

Asimismo, tenemos la opinión de Alfaro Valverde (2011) sobre la indemnización al cónyuge perjudicado, quien indica lo siguiente:

La regulación normativa de la indemnización (...) adolece de una serie de imprecisiones y omisiones, tanto de orden sustantivo como procesal, lo que podría traducirse en un falso concepto de esta entendiéndola más que como un mecanismo destinado a evitar inequidades patrimoniales manifiestas entre los cónyuges, como una sanción aplicada sin límite temporal y asociada a la culpabilidad de uno de ellos; de tal manera pensamos que aún queda una larga tarea doctrinal y jurisprudencial por hacer para poder afinar coherentemente el estudiado instituto (p.142).

El falso concepto de la indemnización al cónyuge perjudicado, en el caso de divorcio por separación de hecho al que hace referencia el autor mencionado, se presenta en la práctica judicial. En efecto, al observar los expedientes judiciales de divorcio, objeto de análisis en el presente trabajo de investigación, nos percatamos que estos no se diferencian de un expediente de divorcio por causal correspondiente a la tendencia divorcio-sanción.

Sobre la base en el desarrollo del marco teórico de la investigación y a los resultados expuestos, podemos afirmar, que siendo la separación de hecho una causal de divorcio que pertenece a la tendencia del divorcio-remedio y que fue incorporada al código civil, con la finalidad de dar solución a las parejas y familias que no podían regularizar su situación legal por no poderse divorciar a pesar de estar separados de hecho; en el Perú, al normar lo correspondiente a la «indemnización al cónyuge perjudicado» como pretensión acumulada legalmente, se ha distorsionado dicha naturaleza y fin generando una influencia negativa en 
la tramitación y duración del proceso de divorcio por separación de hecho, en perjuicio de los propios cónyuges e, incluso, de los otros miembros de la familia.

\section{DISCUSIÓN}

La indemnización al cónyuge perjudicado tal y como se plantea en el derecho comparado y como se ha precisado en el presente trabajo, posee una naturaleza objetiva, sin embargo, en la práctica su utilización ha sido distorsionada por parte de los operadores del derecho, situación que se debe a la imprecisión de la norma en nuestro país, por ello su influencia sobre el proceso de divorcio por separación de hecho es negativa en este tipo de divorcio que pertenece al sistema remedio, pues genera mayor grado de beligerancia. La distorsión a la que nos referimos, es la utilización de la "pretensión de indemnización en caso de perjuicio" como revancha o venganza por parte del cónyuge demandado y a su aplicación como sanción a uno de los consortes por parte de los jueces.

Además de lo manifestado, aplicando las diversas situaciones procesales que implican la acumulación de la obligación legal de indemnizar al cónyuge perjudicado en este proceso, ciertamente influye en su duración y tramitación, veamos:

En la práctica ocurre que — de no acumularse la pretensión indemnizatoria por las partes, ni ser determinada por el juez-, el proceso de divorcio por separación de hecho tendría una tramitación simple por debatirse una causal objetiva de la tendencia del divorcio-remedio; del mismo modo, la situación sería menos controversial que cuando se posibilita a los cónyuges y al juzgador acumular la pretensión de indemnización, puesto que en este segundo supuesto los cónyuges se atribuirán recíprocamente conductas culposas para justificar su petitorio; en el supuesto que las partes aleguen perjuicio y en el caso que el juez, sobre la base del petitorio implícito y de los propios hechos, determine al cónyuge perjudicado y establezca una indemnización o adjudicación preferente de bienes. Del mismo modo, la parte que se considere perjudicada por esta decisión resistirá a las imputaciones y recurrirá a la segunda instancia e incluso, a la casación. 
Además de lo mencionado, el hecho de haberse establecido la procedencia de la indemnización en estudio — no solo a cargo de las partes, sino también por parte del juez-, implica que respecto de una pretensión personalísima, el juzgador debe sancionar de oficio una indemnización o adjudicación de bienes en favor de uno de los cónyuges, siempre que este haya expresado en el curso del proceso hechos concretos referidos a su condición de cónyuge perjudicado; consideramos que esta declaración de oficio genera que en el proceso de divorcio por separación de hecho, la parte que se sienta perjudicada por la determinación del cónyuge perjudicado, deduzca nulidades y plantee impugnaciones que dilatarán el proceso. Al respecto, saludamos la posición del Tribunal Constitucional en la Sentencia N. ${ }^{\circ}$ 00782-2013-PA/TC del 25 de marzo del 2015, sin dejar de considerar que esta es relativamente reciente.

Otro aspecto a tener en cuenta es el referido a la carga de probar, pues la indemnización en la separación de hecho no solamente debe ser alegada sino que también debe ser probada, debiendo ofrecerse los medios de prueba destinados a demostrar la situación de perjuicio generado al cónyuge que solicite la indemnización. El tema de la carga de la prueba, tendrá por objetivo, demostrar la situación de perjuicio generado por la ruptura de la convivencia y las demás circunstancias que el juez valorará, esta situación —evidentemente- implica mayor actividad probatoria, que en la práctica se traduce en mayor tiempo de tramitación y también posiciones controversiales, en algunos casos extremos.

Prácticamente durante todo el desarrollo del proceso de divorcio por separación de hecho, este será pasible de la incorporación o acumulación de la pretensión de indemnización — por las partes o de oficio por el juez-; lo cual demuestra que el proceso de divorcio por causal de separación de hecho, se encuentra fuertemente influenciado por la obligación legal de indemnizar. Esta posibilidad de incorporación de la indemnización durante el trámite del proceso de divorcio, implica también la posibilidad de desarrollar mayor actividad procesal y, sobre todo, de agregar mayor grado de beligerancia al proceso. La flexibilización de la incorporación de pruebas en este proceso de divorcio, genera dilaciones y, en algunos casos, alienta conductas maliciosas. 
La situación referida al petitorio implícito también convertirá al proceso de divorcio que nos ocupa, en un proceso lato y complejo, pues la posibilidad de que se resuelva la pretensión de indemnización derivada de la separación de hecho, no solo está sujeta a ser peticionada por las partes (principio de congruencia), sino que también es posible de ser determinada de oficio por el juez. El proceso será más lato porque quien se considere afectado por la decisión del juzgador respecto a haber dispuesto la actuación de una prueba de oficio hará uso de los remedios y recursos que la ley procesal le concede, como son: deducir nulidades e impugnar y, posiblemente, será más controversial porque la parte que no se sienta favorecida con la sentencia en el aspecto referido a la indemnización, considerará argumentos destinados a contradecir los que sustentaron la decisión del juzgador.

Sobre este punto, consideramos que los juzgadores pueden incurrir en subjetividades que, en algunos casos, pueden llegar a la arbitrariedad, por ejemplo: considerar perjudicado a quien no se siente así ni pretende indemnización alguna.

Este análisis, referido a la influencia de la acumulación de la obligación legal de indemnizar en el proceso de divorcio por separación de hecho, se corrobora con los datos obtenidos de los expedientes judiciales tramitados en el Juzgado de Familia de La Convención, Región Cusco, periodo 2009 a 2012.

\section{CONCLUSIONES}

Primera.- El 'divorcio-remedio’ es un sistema objetivo de disolución matrimonial que a diferencia del 'divorcio-sanción', prescinde de la culpa de uno de los cónyuges y se funda en la ruptura de la convivencia conyugal sin indagar sus motivaciones. Su incorporación en las legislaciones obedece a la tendencia de superar el concepto de culpa por el fracaso matrimonial, así como evitar que las relaciones familiares se deterioren más por el mismo proceso de divorcio. En nuestro país, mediante ley n. ${ }^{\circ} 27495$ del 07 de julio de 2001, se incorporó como causal de divorcio la separación de hecho de los cónyuges, la cual pertenece al sistema 'divorcio-remedio'. 
Segunda.- La separación de hecho es una causal objetiva de divorcio, que se configura con la comprobación del hecho de la ruptura de la vida en común por el tiempo establecido en la norma jurídica; fue acogida en el Perú con la finalidad de regularizar la situación conyugal de aproximadamente un millón de personas separadas, buscando dar solución a la existencia de matrimonios ficticios y familias desprotegidas legalmente debido a los impedimentos de las parejas de contraer matrimonios o conformar una convivencia legal. Por pertenecer al sistema o tendencia 'divorcio-remedio', el procedimiento judicial de divorcio por esta causal debería ser de corta duración y menos complejo o controversial que un proceso de 'divorciosanción'.

Tercera.- El segundo párrafo del artículo 345 A del Código Civil, incorporado por ley n. ${ }^{\circ}$ 27495, dispone como acumulación legal al proceso de divorcio por separación de hecho, la indemnización en caso de perjuicio. Tal situación implica la identificación de un cónyuge perjudicado que debe protegerse, hecho que requiere mayor debate probatorio para determinar el perjuicio y la indemnización en su monto y forma.

Cuarta.- El Tercer Pleno Casatorio Civil Peruano convocado en diciembre del 2010, recaído en la casación n. ${ }^{\circ}$ 4664-2010-Puno, ha establecido con carácter de jurisprudencia vinculante, que la indemnización al cónyuge perjudicado tiene la naturaleza de una obligación legal, cuya finalidad es corregir un evidente desequilibrio económico e indemnizar el daño a la persona resultante de la separación de hecho o del divorcio en sí. Su fundamento no es la responsabilidad civil contractual o extracontractual, sino la equidad y la solidaridad familiar. No obstante ello, la interpretación errónea que realizan los operadores del derecho, respecto a la indemnización, genera una distorsión en su aplicación y debido a ello se produce una influencia negativa en la tramitación del proceso de divorcio por separación de hecho.

Quinta.- En la presente investigación ha quedado demostrado que en el 61,54 \%; en el 100\% y, en el 92,31 \% de los procesos judiciales analizados, la obligación legal de indemnizar al cónyuge perjudicado influye en la duración y tramitación del proceso de divorcio por la causal de separación de hecho, extendiéndolo y tornándolo complejo en la Región Cusco, Provincia de La Convención, en el periodo comprendido entre el 2009 - 2012. 
Sexta.- El proceso de divorcio por separación de hecho perteneciente al sistema de divorcio remedio — que ya es tramitado en la vía procedimental más larga y compleja del sistema procesal civil peruano (proceso de conocimiento) — , al poseer como acumulación legal obligatoria la indemnización en caso de perjuicio, en la práctica judicial pierde su esencia y se asemeja a un proceso de divorcio por causal, perteneciente al sistema de divorcio-sanción por la duración y grado de beligerancia.

Séptima.- El proceso de divorcio por separación de hecho, debe ventilarse a través de un proceso judicial sencillo cuyo desarrollo debe ser menos complejo que aquellos en los que se invocan otras causales que corresponden a la tendencia del 'divorcio-sanción', en consecuencia, corresponde idear un proceso de tutela sumaria o diferenciada, para los procesos de divorcio por causal de separación de hecho, con la finalidad de tutelar de manera oportuna y adecuada a quienes consideran tener derecho al divorcio por dicha causa. Ello para evitar la situación beligerante y de confrontación en la que se torna un proceso de divorcio de esta naturaleza, que deteriora mucho más las relaciones familiares ya de por sí, resquebrajadas.

Octava.- Consideramos que la pretensión de indemnización al cónyuge perjudicado, es una pretensión autónoma de carácter personalísimo, que solo debe proceder a pedido de parte y dentro de un plazo determinado, puesto que los matrimonios, en la actualidad, no responden a los esquemas tradicionales.

Décima.- Concluido el proceso de divorcio por separación de hecho, el cónyuge que, se considere perjudicado podrá promover un proceso de indemnización, en una causa independiente.

\section{AGRADECIMIENTOS}

Este estudio ha sido posible por el apoyo e interés en promover la investigación en derecho del personal que labora en el Juzgado de Familia, Archivo Modular y Archivo Central de la Corte Superior de Justicia del Cusco sede Quillabamba, provincia de La Convención, Cusco Igualmente, ha sido valiosa la colaboración del Mg. Fernando Murillo Flores y Dr. Pavel 
Valer Bellota, quienes tuvieron la paciencia de analizar y discutir los contenidos del estudio, brindando valiosas apreciaciones que han enriquecido el artículo.

\section{Fuentes de financiamiento}

Propia

\section{Conflictos de interés}

La autora declara no tener conflictos de interés en la publicación de este artículo.

\section{BIBLIOGRAFÍA}

Alfaro Valverde, L. (2011). La Indemnización en la Separación de Hecho, Análisis del Formante Jurisprudencial y Doctrinal. Lima: Gaceta Jurídica S.A.

Borda, G. (2015). Divorcio sanción-divorcio remedio. En Derecho Civil Extrapatrimonial y Responsabilidad Civil (págs. 90-91). Lima: Gaceta Jurídica S.A.

Cabello Matamala, C. J. (2001). Divorcio Remedio en el Perú. Derecho PUCP.

Calisaya Marquez, A. (2013). El divorcio en Perú y España. En A. A. Calisaya Márquez, El Divorcio en la Legislación, Doctrina y Jurisprudencia, Primera Edición (págs. 357358). Lima: Gaceta Jurídica S.A.

Herrera, M. (s.f.). Una mirada crítica y actual sobre el divorcio vincular en el MERCOSUR y paises asociados a la Luz de los Derecho Humanos. Obtenido de Bilioteca Virtual del Instituto de Investigaciones Jurídicas de la Universidad Autónoma de México: http:/www.jurídicas.unam.mx

Peterka, N. (27-29 de junio de 2006). El Divorcio Francés tras la ley del 26 de mayo de 2004. Un divorcio bajo la influencia de la voluntad. Familia, Matrimonio y divorcio en los albores del siglo XXI. Jornadas Internacionales sobre las Reformas del Derecho de Familia, Ponencias y Comunicaciones. Madrid, España: IDADFE-UNED-EI Derecho Editores.

Ramos Núñez, C. A. (2014). Cómo hacer una tesis de Derecho. Lima. Ed. Grijley

Suarez Farfán, A. (Consulta 30-01-14 de marzo de 2007). ¡Divorciarme! ¿Por la causal de separación de hecho? Obtenido de Una aproximación a la incompatibilidad normativa generada por la causal de separación de hech inntroducida a nuestra lista taxativa de causales de divorcio: http/www.derechovirtual.com 